\title{
Morphometric Study of Posterior Cranial Fossa Using Computerized Tomographic (CT) Images
}

\author{
Hemalata Rath ${ }^{1}$, Subhadra Devi Velichety', Lakshmi AY ${ }^{3}$, Thyagaraju K ${ }^{4}$, Pavan P Havaldar ${ }^{5}$ \\ ${ }^{1}$ Tutor, Gadag institute of Medical Sciences, Karnataka, ${ }^{2}$ Professor of Anatomy, SVIMS- Sri Padmavathi Medical College for women, Tirupati, ${ }^{3}$ Professor of \\ Radiology, SVIMS, Tirupati, ${ }^{4}$ Assistant professor of Anatomy, SVIMS, Tirupati, ${ }^{5}$ Associate professor of Anatomy, GIMS, Gadag.
}

\section{Abstract}

Introduction: The posterior cranial fossa is the largest and the deepest of the three fossae. Contents of posterior cranial fossa include occipital part of cerebral hemispheres, cerebellum, midbrain, pons and medulla oblongata. Variations in the volume of posterior cranial fossa may cause compression of these structures which may lead to various disorders. There is increasing evidence on the diagnostic potential of posterior cranial fossa measurements. The present study on morphometry of posterior cranial fossa based on CT images of patients without any clinical abnormality was undertaken for the first time in south Indian population. Subjects and Methods: To study and compare sex-wise and age-wise differences in the supratentorial and posterior cranial fossa (PF) measurements in the normal CT scan images of 62 males and 38 females who attended the Neurology department of SVIMS belonging to Rayalaseema region was undertaken. The measurements that were recorded are transverse diameter (TD) and anteroposterior diameter (APD) of supratentorial part and also posterior cranial fossa and height and volume of posterior cranial fossa. Results: The mean supratentorial TD and APD were found to be less in male but were not statistically significant sex-wise and age-wise. The mean posterior fossa APD was significant, PF height and volume were highly significantly in males. Discussion: There are no reports on supratentorial parameters in literature for comparing the results of present study. Except for one study on CT on height and volume of posterior cranial fossa there are no other studies for comparing the values of present study. Conclusion: Observations on supratentorial parameters of the present study are the first to be reported in literature.Age-wise and sex-wise observation of parameters of TD and APD of PF are the first to be reported in literature.

Keywords: Basion, computerized tomographic scan, internal occipital protuberance, Mc Rae line, opisthion, posterior cranial fossa, supratentorial, Twinning's line, tuberculum sellae, torcula.

Corresponding Author: Dr. Hemalata Rath, Tutor, Gadag institute of Medical Sciences, Karnataka.

Received: December 2018

Accepted: January 2019

\section{Introduction}

Knowledge of normal anatomy of a region is important to the clinician for better diagnosis, classification and treatment of diseases related to the region and serve as a future reference for defining an anatomic range.

Pathological conditions of posterior cranial fossa (PF) and cranio-vertebral junction are very common. Knowledge of anatomy of this region and the normal range of dimensions of these regions are important for proper planning of medical/surgical line of management. A wide spectrum of central nervous system diseases has been associated with alterations in size, shape and contents of posterior cranial fossa such as Chiari malformations, Dandy-Walker syndrome, autism, olivo-Ponto-cerebellar atrophy, cerebellar vermian hypoplasia, Down's Syndrome etc, ${ }^{[1-6]}$ the measurement of volume of posterior cranial fossa and its relationship with supra tentorial volume is of great clinical significance in the diagnosis and prognosis of Chiari malformations.

The parameters of posterior cranial fossa region may present variations depending on race, religion, body habitus, gender, geographical and genetic factors. ${ }^{[7]}$ In the literature only one study on posterior cranial fossa using radiological method on North Indian population was available. The radiological measurement of the posterior cranial fossa is the easiest method to obtain these parameters.

In the literature the supratentorial volume is correlated with the endocranial capacity. ${ }^{[10]}$ Dimensions of supratentorial region alone are not quoted in the literature to the best of our knowledge. The dimensions of supratentorial region are helpful in the study of low grade supratentorial tumours like astrocytoma, ganglioglioma, oligodendroglioma etc. These dimensions are essential in the neurosurgeries involving supratentorial tumours, atrophies. ${ }^{[8]}$

There are limited studies on the morphology of the posterior cranial fossa $(\mathrm{PF})$. There is only one reported study on posterior cranial fossa measurements in dry skulls by Gautam Kanodia et al, ${ }^{[7]}$ who conducted studies on posterior fossa in 100 dry skulls. They reported that the mean height of PF in dry skulls as $3.01 \mathrm{~cm}( \pm 0.22)$ (range $2.5-4.0 \mathrm{~cm}$ ) and volume as $122.49 \mathrm{~cm} 3( \pm 14.66)$. 
Most of the reported studies available in literature on CT scan morphometry of posterior cranial fossa were on patients with Chiarimal formations or on those with underlying pathologies in posterior cranial fossa. ${ }^{[9-13]}$

Prassopoulos et.al., ${ }^{[8]}$ studied the developmental changes in children using Computerised tomography. They reported rapid increase in the volume of posterior fossa during first 3 years of life and later the rate of growth decreases. The values at the age of 3 years are $165 \mathrm{~cm} 3$ in boys and $155 \mathrm{~cm} 3$ in girls. At the age of 15 the values are $220 \mathrm{~cm} 3$ in boys and $207 \mathrm{~cm} 3$ in girls.

Sabri et.al, ${ }^{[11]}$ conducted studies in paediatric patients of 612 years age group on posterior cranial fossa using magnetic resonance imaging with different pathologies underlying and compared with the controls. They reported reduction in all the values in children with underlying pathology. They reported for anteroposterior diameter (APD) of $60.4 \pm 10.6$ $\mathrm{mm}$ in patients and $74.7 \pm 3.5 \mathrm{~mm}$ in controls. Height of posterior fossa in patients is $124.7 \pm 15.7 \mathrm{~mm}$ and in controls is $141.2 \pm 6.8 \mathrm{~mm}$ in their study.

Gautam Kanodia et.al, ${ }^{[7]}$ conducted studies on posterior fossa in $100 \mathrm{CT}$ scans. They reported that the mean height of $\mathrm{PF}$ in $\mathrm{CT}$ was $3.52 \mathrm{~cm}( \pm 0.43)$ and the mean value of PFV were $157.88( \pm 27.94) \mathrm{cm} 3$ (range $98.75-216.88 \mathrm{~cm} 3$ ) and 159.58 ( \pm 25.73 ) cm3(range 116.03-252.99 cm3).

Apolito et.al, ${ }^{[9]}$ conducted morphometric and volumetric studies on posterior fossa in three groups of paediatric patients.

\section{Subjects and Methods}

A prospective study of one hundred (100) computerized tomographic (CT) scan images collected from department of Radiology, Sri Venkateswara Institute of Medical Sciences, Tirupati, Andhra Pradesh were utilized for observing morphological parameters and for recording morphometric parameters of posterior cranial fossa. CT scans of patients admitted to neuro-surgery unit with general complaints of headache and dizziness and without any bony or soft tissue abnormalities were included in the study. Those with fracture, hematoma, or lesions were excluded from the study.

\section{Study Sample}

In the present study using SOMATOM CT scanner, $100 \mathrm{CT}$ scan images of normal individuals of both sexes and in the age group of 6-80years were taken with a slice thickness of $6 \mathrm{~mm}$. The CT scans were evaluated for the following morphological and morphometric parameters of posterior cranial fossa.

\section{A. Supra tentorial part [Figure 1]}

1. Anteroposterior diameter (APD)- distance measured from anterior part of frontal crest to the internal occipital protuberance.

2. Transverse diameter (TD)-the maximum horizontal distance from the mid-point of the AP diameter.

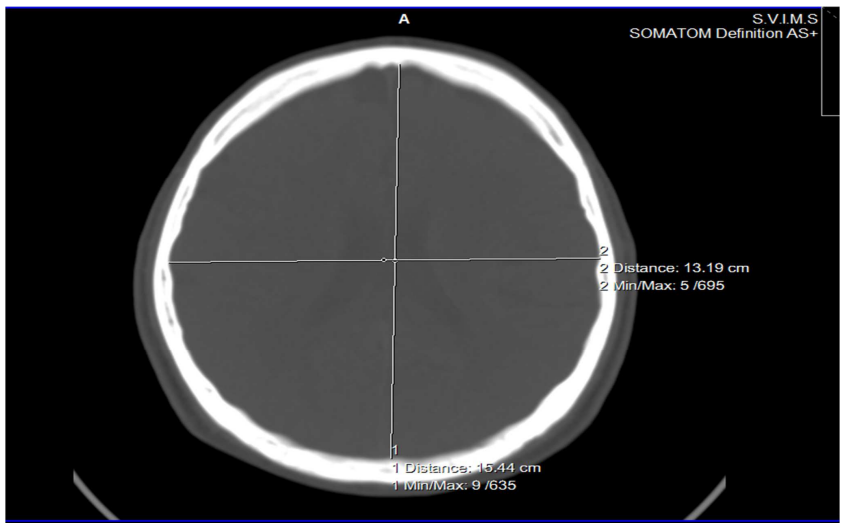

Figure 1: APD and TD of supratentorial partpart

B. Posterior fossa (PF) [Figure 2,3]

1. Height of $\mathrm{PF}$ is perpendicular distance between the following two lines ${ }^{[7]}$ [Figure 2]

- Twinning's line-line between tuberculumsellae and torcula.

- Mc Rae line-radiographic line drawn on sagittal section of CT or MRI, joining the opisthion and basion.

2. Anteroposterior diameter (APD) - distance between posterior clinoid process and internal occipital protuberance. ${ }^{[7]}$ [Figure 4.5]

3. Transverse diameter (TD)-distance measured at right angles to the anteroposterior diameter of posterior cranial fossa. ${ }^{[7]}$ [Figure 3]

4. Volume is measured using the formula ${ }^{[7]}$ $\mathrm{abc} / 2$ where

'a' is height

' $b$ ' is AP diameter

' $c$ ' is transverse diameter

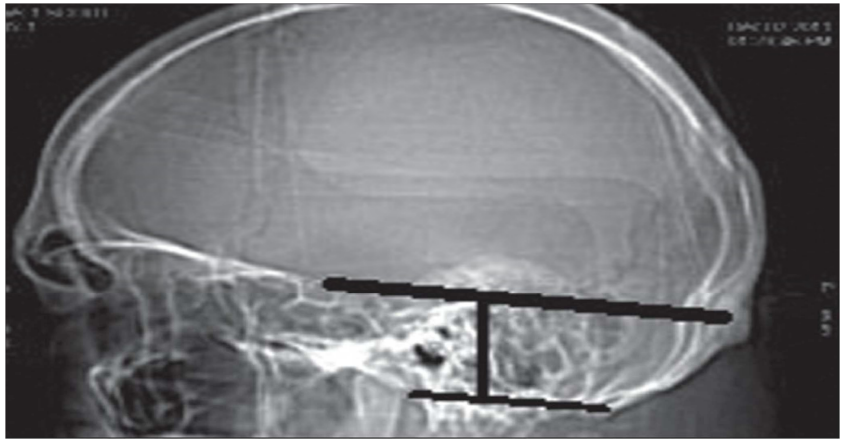

Figure 2: A. Twinning's line-line B.Mc Rae line

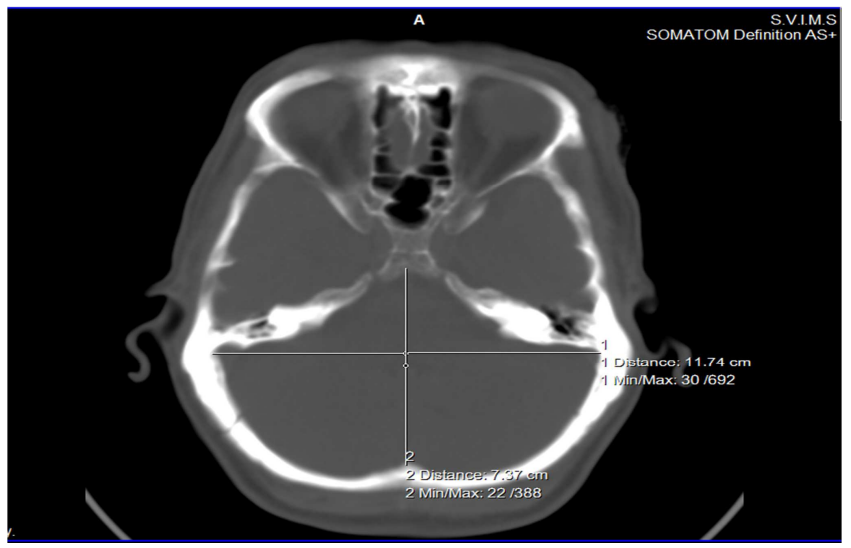

Figure 3: APD and TD of Posterior cranial fossa 
Majority of the subjects were males (62\%) than females $(38 \%)$. Age-wise distribution of subjects was represented in [Figure 4].

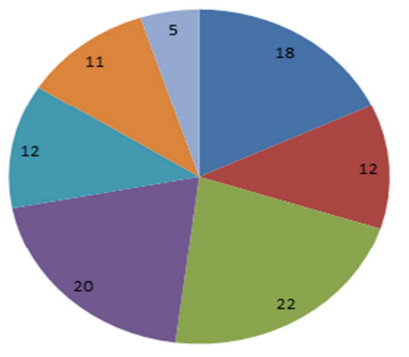

Figure 4: Age distribution (\%) of subjects

Age and gender wise distribution of subjects were presented in [Figure 5]. The age distribution of subjects was found to be similar in both males and females. The differences in the proportion between male and female subjects were also not statistically significant $(\mathrm{P}=0.78$; NS).

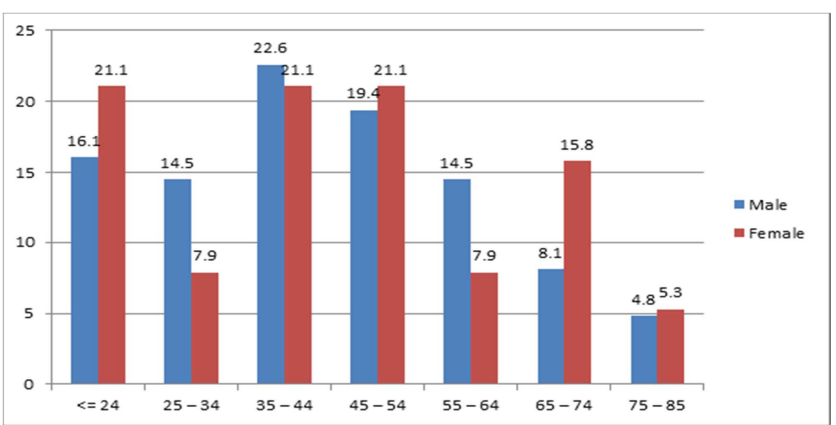

Fig 5: Age and sex distribution (\%) of subjects

\section{A. Analysis of supra tentorial part parameters:}

The results on morphometric parameters of TD and APD of supratentorial part were represented in [Tables $1 \& 2$ ] based on gender and age respectively. These two values were not statistically significant in both gender wise and age wise groups.

Table 1: Supra tentorial transverse and anteroposterior diameter by gender

\begin{tabular}{|l|l|l|}
\hline \multirow{2}{*}{ Gender } & \multicolumn{2}{|l|}{ Supratentorial diameters (Mean \pm SD) } \\
\cline { 2 - 3 } & Transverse & Anteroposterior \\
\hline Male & $12.24 \pm 0.53$ & $14.98 \pm 0.74$ \\
\hline Female & $12.39 \pm 0.59$ & $15.06 \pm 0.68$ \\
\hline Statistical & $\mathrm{t}=1.31 ;$ & $\mathrm{t}=0.56 ;$ \\
significance & $\mathrm{P}=0.19 ; \mathrm{NS}$ & $\mathrm{P}=0.58 ; \mathrm{NS}$ \\
\hline
\end{tabular}

Table 2: Supratentorial transverse and anteroposterior diameter by age group

\begin{tabular}{|l|l|l|}
\hline \multirow{2}{*}{ Age group } & \multicolumn{2}{|l|}{ Supratentorial diameters (Mean \pm SD) } \\
\cline { 2 - 3 } & Transverse & Anteroposterior \\
\hline$<=24$ & $12.44 \pm 0.57$ & $14.97 \pm 0.70$ \\
\hline $25-34$ & $11.95 \pm 0.64$ & $15.07 \pm 0.54$ \\
\hline $35-44$ & $12.31 \pm 0.59$ & $15.04 \pm 0.80$ \\
\hline $45-54$ & $12.42 \pm 0.48$ & $15.05 \pm 0.83$ \\
\hline $55-64$ & $12.11 \pm 0.50$ & $14.96 \pm 0.69$ \\
\hline $65-74$ & $12.38 \pm 0.45$ & $15.06 \pm 0.68$ \\
\hline $75-85$ & $12.38 \pm 0.67$ & $14.72 \pm 0.81$ \\
\hline $\begin{array}{l}\text { Statistical } \\
\text { significance }\end{array}$ & $\mathrm{F}=1.43 ;$ & $\mathrm{F}=0.19 ;$ \\
& $\mathrm{P}=0.21 ; \mathrm{NS}$ & $\mathrm{P}=0.97 ; \mathrm{NS}$ \\
\hline
\end{tabular}

\section{B. Analysis of Posterior fossa parameters:}

The results on morphometric parameters of TD and APD of posterior fossa, height of posterior fossa and volume of posterior fossa were represented gender-wise and sex-wise in [Tables 3-8]. The mean posterior fossa TD was found to be similar in the male and female subjects and the difference was not statistically significant $(\mathrm{P}=0.60)$. The mean posterior fossa APD was however found to be significantly higher in males (7.06) compared to that in females (6.74) and the difference was statistically significant $(\mathrm{P}=0.02 ; \mathrm{S})$ [Table 3].

Table 3: Posterior fossa transverse and anteroposterior diameter by gender

\begin{tabular}{|l|l|l|}
\hline \multirow{2}{*}{ Gender } & \multicolumn{2}{|l|}{ Posterior fossa diameters (Mean \pm SD) } \\
\cline { 2 - 3 } & Transverse & Anteroposterior \\
\hline Male & $10.63 \pm 0.54$ & $7.06 \pm 0.59$ \\
\hline Female & $10.69 \pm 0.55$ & $6.74 \pm 0.73$ \\
\hline Statistical & $\mathrm{t}=0.52 ;$ & $\mathrm{t}=2.41 ;$ \\
significance & $\mathrm{P}=0.60 ; \mathrm{NS}$ & $\mathrm{P}=0.02 ; \mathrm{S}$ \\
\hline
\end{tabular}

The mean posterior fossa transverse and anteroposterior diameters were found to be similar in the various age groups and the differences were not statistically significant $(\mathrm{P}=0.76$; NS). [Table 4].

Table 4: Posterior fossa transverse and anteroposterior diameter by age group

\begin{tabular}{|l|l|l|}
\hline \multirow{2}{*}{ Age group } & \multicolumn{2}{|l|}{ Posterior fossa diameters $($ Mean \pm SD) } \\
\cline { 2 - 3 } & Transverse & Anteroposterior \\
\hline$<=24$ & $10.70 \pm 0.57$ & $6.67 \pm 0.75$ \\
\hline $25-34$ & $10.73 \pm 0.50$ & $7.05 \pm 0.69$ \\
\hline $35-44$ & $10.66 \pm 0.58$ & $6.94 \pm 0.51$ \\
\hline $45-54$ & $10.71 \pm 0.46$ & $7.05 \pm 0.65$ \\
\hline $55-64$ & $10.40 \pm 0.72$ & $6.83 \pm 0.68$ \\
\hline $65-74$ & $10.71 \pm 0.48$ & $7.22 \pm 0.61$ \\
\hline $75-85$ & $10.61 \pm 0.36$ & $6.82 \pm 0.78$ \\
\hline $\begin{array}{l}\text { Statistical } \\
\text { significance }\end{array}$ & $\mathrm{F}=0.56 ;$ & $\mathrm{F}=1.08 ;$ \\
& $\mathrm{P}=0.76 ; \mathrm{NS}$ & $\mathrm{P}=0.38 ; \mathrm{NS}$ \\
\hline
\end{tabular}

The mean posterior fossa height was found to be significantly higher in male subjects (3.57) compared to that in females (3.12) and the difference was also very highly significant $(\mathrm{P}<0.001 ; \mathrm{S})$ [Table 5].

Table 5: Posterior fossa height by gender

\begin{tabular}{|l|l|}
\hline Age group & $\begin{array}{l}\text { Posterior fossa height } \\
\text { (Mean } \pm \text { SD) }\end{array}$ \\
\hline Male & $3.57 \pm 0.35$ \\
\hline Female & $3.12 \pm 0.35$ \\
\hline Statistical significance & $\begin{array}{l}\mathrm{t}=6.20 ; \\
\end{array}$ \\
$\mathrm{P}<0.001 ; \mathrm{S}$ \\
\hline
\end{tabular}

The mean posterior fossa height was found to be similar in the various age groups and the differences were also not statistically significant ( $\mathrm{P}=0.36$; NS) [Table 6].

\begin{tabular}{|l|l|}
\hline Table 6: Posterior fossa height by age group \\
\hline Age group & $\begin{array}{l}\text { Posterior fossa height } \\
\text { (Mean } \pm \text { SD) }\end{array}$ \\
\hline$<=24$ & $3.37 \pm 0.46$ \\
\hline $25-34$ & $3.50 \pm 0.50$ \\
\hline $35-44$ & $3.35 \pm 0.31$ \\
\hline $45-54$ & $3.41 \pm 0.34$ \\
\hline $55-64$ & $3.41 \pm 0.46$ \\
\hline $65-74$ & $3.22 \pm 0.37$ \\
\hline $75-85$ & $3.73 \pm 0.52$ \\
\hline Statistical significance & $\begin{array}{l}\mathrm{F}=1.11 ; \\
\mathrm{P}=0.36 ; \mathrm{NS}\end{array}$ \\
\hline
\end{tabular}




\section{Rath et al; Marphametric Study of Pasteriar Cranial Fassa Using Camputerized Tamagraphic Images}

The mean posterior fossa volume was found to be significantly higher in male subjects (134.5) compared to that in females (113.7) and the difference was also very highly significant $(\mathrm{P}<0.001 ; \mathrm{S})$ [Table 7].

\begin{tabular}{l}
\hline Table 7: Posterior fossa volume by gender \\
\begin{tabular}{|l|l|}
\hline Age group & $\begin{array}{l}\text { Posterior fossa volume } \\
(\text { Mean } \pm \text { SD })\end{array}$ \\
\hline Male & $134.46 \pm 21.04$ \\
\hline Female & $113.73 \pm 25.11$ \\
\hline Statistical significance & $\mathrm{t}=4.43 ;$ \\
& $\mathrm{P}<0.001 ; \mathrm{S}$ \\
\hline
\end{tabular}
\end{tabular}

The mean posterior fossa volume was found to be similar in the various age groups and the differences were also not statistically significant $(\mathrm{P}=0.76$; NS) [Table 8].

Table 8: Posterior fossa volume by age group

\begin{tabular}{|l|l|}
\hline Age group & $\begin{array}{l}\text { Posterior fossa volume } \\
\text { (Mean } \pm \text { SD) }\end{array}$ \\
\hline$<=24$ & $121.33 \pm 25.96$ \\
\hline $25-34$ & $133.67 \pm 29.13$ \\
\hline $35-44$ & $124.65 \pm 21.00$ \\
\hline $45-54$ & $129.62 \pm 22.95$ \\
\hline $55-64$ & $122.28 \pm 26.29$ \\
\hline $65-74$ & $125.81 \pm 26.08$ \\
\hline $75-85$ & $136.88 \pm 31.08$ \\
\hline Statistical significance & $\begin{array}{l}\mathrm{F}=0.56 ; \\
\mathrm{P}=0.76 ; \mathrm{NS}\end{array}$ \\
\hline
\end{tabular}

\section{Discussion}

Overcrowding of posterior cranial fossa (PF) can be determined if the normal range of the volume and height are available. ${ }^{[7]}$ Short height of PF and underdeveloped bony structures could lead to downward herniation of the contents in adults and in paediatric patients could result in syringomyelia due to obstruction of the normal CSF circulation. This indicates the importance of normal values in the clinical approach.
Very limited literature was available on morphometric parameters of posterior cranial fossa by normal CT studies. Hence in the present study all the parameters on supratentorial and posterior fossa could not be compared with the literature.

Observations on supratentorial parameters of the present study are the first to be reported in literature. The mean supratentorial TD was found to be less in male (12.24 \pm $0.53)$ than in female $(12.39 \pm 0.59)$ subjects. They are more or less similar in different age groups. The mean supratentorial APD was found to be less in male (14.98 \pm $0.74)$ than in female $(15.06 \pm 0.68)$ subjects. They are more or less similar indifferent age groups. These dimensions are helpful in the study about supratentorial gliomas and supratentorial tumours. ${ }^{[8]}$

The gender-wise and age-wise differences in TD and APD of supra tentorial part of posterior cranial fossa were not statistically significant in the present study. There are no reported values in literature for comparing these parameters. The mean posterior fossa TD was found to be similar in the male and female subjects and the difference was not statistically significant $(\mathrm{P}=0.60)$. There were no reports in literature for comparing this parameter.

The mean posterior fossa APD was significantly higher in males $(7.06 \mathrm{~cm})$ compared to that in females $(6.74 \mathrm{~cm})$ and the difference was statistically significant $(\mathrm{P}=0.02 ; \mathrm{S})$. The only reported value in literature was a mean of $7.47 \mathrm{cms}$ for APD by Sabriet.al, ${ }^{[1]}$ [Table 6,5] based on MRI in both sexes together. The combined mean $36 \mathrm{~mm}$ in the present study for APD was less than that reported by Sabriet.al. ${ }^{[1]}$

The mean posterior fossa TD and APD were found to be similar in various age groups and the differences were also not statistically significant $(\mathrm{P}=0.76 ; \mathrm{P}=0.38)$. There are no reports in literature on this parameter.

The mean posterior fossa height was found to be significantly higher in male subjects (3.57) compared to that in females (3.12) and the difference was also very highly significant $(\mathrm{P}<0.001 ; \mathrm{S})$.

Table 9: Comparison of Mean posterior fossa parameters reported in literature with that of present study

\begin{tabular}{|c|c|c|c|c|c|c|c|c|}
\hline $\begin{array}{l}\text { Author and method of } \\
\text { observation }\end{array}$ & \multicolumn{2}{|c|}{ Height(cm) } & \multicolumn{2}{|c|}{ Volume (cm3) } & \multicolumn{2}{|l|}{ APD $(\mathbf{m m})$} & \multicolumn{2}{|l|}{$\begin{array}{l}\text { TD } \\
(\mathbf{m m})\end{array}$} \\
\hline $\begin{array}{l}\text { Gautam Kanodia et al [7] } \\
(\mathrm{CT})\end{array}$ & $\begin{array}{l}3.55 \mathrm{~cm} \\
(\mathrm{M})\end{array}$ & $3.46 \mathrm{~cm}(\mathrm{~F})$ & $\begin{array}{l}162.88 \mathrm{~cm} 3 \\
(\mathrm{M})\end{array}$ & $\begin{array}{l}148.99 \mathrm{~cm} 3 \\
(\mathrm{~F})\end{array}$ & \multicolumn{2}{|l|}{-} & \multicolumn{2}{|l|}{-} \\
\hline $\begin{array}{l}\text { Gautam Kanodia et al [7] } \\
\text { (Dry bones) }\end{array}$ & \multicolumn{2}{|c|}{$3.01 \mathrm{~cm}$} & \multicolumn{2}{|c|}{$122.49 \mathrm{~cm} 3$} & \multicolumn{2}{|l|}{-} & \multicolumn{2}{|l|}{-} \\
\hline $\begin{array}{l}\text { Sabri et al [11] } \\
\text { MRI }\end{array}$ & $\begin{array}{l}141.2 \mathrm{~mm} \\
(\mathrm{~N})\end{array}$ & $\begin{array}{l}124.7 \mathrm{~mm} \\
(\mathrm{Pt})\end{array}$ & - & - & $74.7 \mathrm{~mm}(\mathrm{~N})$ & $\begin{array}{l}60.4 \mathrm{~mm} \\
(\mathrm{Pt})\end{array}$ & & \\
\hline \multirow{2}{*}{$\begin{array}{l}\text { Triglydas et.al, [13] } \\
\text { (MRI) }\end{array}$} & & & 146.83(AS) & $127.4(\mathrm{~S})$ & & & & \\
\hline & & & \multicolumn{2}{|c|}{$107.19(\mathrm{~N})$} & & & & \\
\hline \multirow{3}{*}{$\begin{array}{l}\text { Prassopoulos [8] } \\
\text { (MRI) }\end{array}$} & & & 3years & 15 years & & & & \\
\hline & & & $165 \mathrm{~cm} 3(\mathrm{M})$ & $155 \mathrm{~cm} 3(\mathrm{~F})$ & & & & \\
\hline & & & $220 \mathrm{~cm} 3(\mathrm{M})$ & $207 \mathrm{~cm} 3(\mathrm{~F})$ & & & & \\
\hline $\begin{array}{l}\text { Present study } \\
\text { (CT) }\end{array}$ & $\begin{array}{l}3.57 \mathrm{~cm} \\
(\mathrm{M})\end{array}$ & $\begin{array}{l}3.12 \mathrm{~cm} \\
(\mathrm{~F})\end{array}$ & $\begin{array}{l}134.5 \mathrm{~cm} 3 \\
(\mathrm{M})\end{array}$ & $\begin{array}{l}113.7 \mathrm{~cm} 3 \\
(\mathrm{~F})\end{array}$ & $\begin{array}{l}7.06 \mathrm{~cm} \\
(\mathrm{M})\end{array}$ & $\begin{array}{l}6.74 \mathrm{~cm} \\
(\mathrm{~F})\end{array}$ & $\begin{array}{l}10.63 \\
\mathrm{Cm}(\mathrm{M})\end{array}$ & $\begin{array}{l}10.69 \mathrm{~cm} \\
\text { (F) }\end{array}$ \\
\hline
\end{tabular}

Comparison of posterior fossa values with previous studies.

$\mathrm{M}=$ male $; \mathrm{F}=$ Female $; \mathrm{N}=$ Normal $; \mathrm{Pt}=$ patients $\mathrm{AS}=$ Asymptomatic Chiari malformation;

$\mathrm{S}=$ Symptomatic Chiari malformation

Gautam Kanodiaet.al, ${ }^{[7]}$ based on observations in100 CT scans reported a mean height of $3.55 \mathrm{~cm}$ in males and 3.46 $\mathrm{cm}$ in females for posterior fossa. The values in both sexes were more or less similar in the present study as that of
Gautam Kanodia.

The mean value of PF volume reported by GautamKanodiaet al, ${ }^{[7]}$ were $157.88( \pm 27.94) \mathrm{cm} 3$ (range $98.75-216.88 \mathrm{~cm} 3$ ) and $159.58( \pm 25.73) \mathrm{cm} 3$ (range 116.03- $252.99 \mathrm{~cm} 3)$ which 
shows a higher value than the present study (Table.9). They also reported the values in dry skulls as mean height of 3.01 $\mathrm{cm}( \pm 0.22)$ (range $2.5-4.0 \mathrm{~cm}$ ) and volume of 122.49 $( \pm 14.66)$, for posterior fossa. The values obtained in dry skulls are less than those obtained by CT studies in their study.

The mean posterior fossa volume was found to be significantly higher in male subjects $(134.5 \mathrm{~cm} 3)$ compared to that in females $(113.7 \mathrm{~cm} 3)$ and the difference was also very highly significant $(\mathrm{P}<0.001 ; \mathrm{S})$ in the present study. The values reported in the literature [Table 9] were greater than the values in the present study in both sexes.

Trigylidaset.al, ${ }^{[13]}$ conducted studies on posterior fossa dimensions and volume using MRI in Canada. They calculated the volume of posterior fossa using Cavalieri method and reported as 107.19 which is lower than the values obtained in the present study using CT findings [Table 9].

Prassapouls, ${ }^{[8]}$ values are also higher than the present study which he reported in normal children between 3-15 years using MRI [Table 9]

Mean posterior fossa height reported by Gautam Kanodia et.al, ${ }^{[7]}$ is similar to the values obtained in the present study in males. In females the values obtained in the present study are less than that reported by Gautam Kanodia et.al. ${ }^{[6]}$ Sabriet.al, ${ }^{[11]}$ reported the value of mean height of posterior fossa as $14.12 \mathrm{cms}$ in MRI studies which was higher than the values obtained in the present study.

The mean posterior fossa height and volume were found to be similar in the various age groups and the differences were also not statistically significant $(\mathrm{P}=0.36 ; \mathrm{P}=0.76)$. There is no reported literature on age-wise study on posterior fossa parameters as was done in the present study.

\section{Conclusion}

All the parameters observed in the present study did not show statistically significant differences. Statistically significant differences between sexes were observed in the APD of posterior fossa, mean posterior fossa height and posterior fossa volume. Between the different age groups the parameters were not significant.

The present study is of great use to radiologists and neurosurgeons, as the morphometric parameters of posterior fossa, are essential for performing surgeries of the craniovertebral junction disorders, supra tentorial tumours etc.
As the present study is performed in controls it forms a base for comparing with that is various cranio-vertebral junction diseases and for determining the extent of neuro-surgical procedure.

Acknowledgement: The authors are thankful to the SVIMS university for facilitating us to undertake this research work.

\section{References}

1. Macdonald DR1, Cascino TL, Schold SC Jr, Cairncross JG. Response criteria for phase II studies of supratentorial malignant glioma $1990 \mathrm{Jul} ; 8(7): 1277-80$.

2. AydinS, HanimogluH, TanriverdiT, YenturE, Kaynar MY. Chiari type malformations in adults: A morphometric analysis of the posterior cranial fossa. Surg. Neurol., 2005; 64:237.

3. Badie B, MendDa D, Batzdorf U. Posterior fossa volume and response to suboccipital decompression in patients with Chiari I malformation. Neurosurgery, 1995;37:214-8.

4. Grant RA, Heuer GG, Carrión GM, Adzick NS, Schwartz ES, Stein SC, et al. Morphometric analysis of posterior fossa after in utero myelomeningocele repair. J NeurosurgPediatr., 2011;7:3628.

5. Tubbs RS, Elton S, Grabb P, Dockery SE, Bartolucci AA, Oakes WJ. Analysis of the posterior fossa in children with the Chiari 0 malformation. Neurosurgery 2001; 48:1050-5.

6. Tubbs RS, Hill M, Loukas M, Shoja MM, Oakes WJ. Volumetric analysis of the posterior cranial fossa in a family with four generations of the Chiari malformation Type I. J NeurosurgPediatr., 2008:1; 21-4.

7. GautamKanodia, Vijay Parihar, Yad R Yadav, Pushp R Bhatele and Dhananjay Sharma. Morphometric analysis of posterior fossa and foramen magnum. J Neurosci Rural Pract. 2012; 3(3): 261266.

8. Prassopoulos D. Cavouras S. Golfinopoulos. Developmental changes in the posterior cranial fossa of children studied by CT Neuroradiology (1996) 38:80-83Springer-Verlag.

9. Apolito JC. Foramen magnum position variation in Pan troglodytes, Plio-Pleistocene hominids, and recent Homo sapiens: Implications for recognizing the earliest hominids. American Journal of Physical Anthropology,2005;127: 267-276.

10. Nishikawa M, Sakamoto H, Hakuba A, Nakanishi N, Inoue Y. Pathogenesis of Chiari malformation: A morphometric study of the posterior cranial fossa. J Neurosurg1997; 86:40-7.

11. Aydin S, Hanimoglu H, Tanriverdi T, Yentur E, Kaynar MY. Chiari type I malformations in adults: a morphometric analysis of theposterior cranial fossa. Surgical Neurology 2005;64(3):237 241.

12. Sgouros S, Kountouri M, Natarajan K. Posterior fossa volume in children with Chiari malformation Type I. J Neurosurg 2006; 105(2 Suppl)

13. Trigylidas T, Baronia B, Vassilyadi M, Ventureyra EC. Posterior fossa dimension and volume estimates in pediatric patients with Chiari I malformations. Childs NervSyst 2008:24;329-36.

Copyright: ( $\odot$ the author(s), publisher. Academia Anatomica International is an Official Publication of "Society for Health Care \& Research Development". It is an open-access article distributed under the terms of the Creative Commons Attribution Non-Commercial License, which permits unrestricted non-commercial use, distribution, and reproduction in any medium, provided the original work is properly cited.

How to cite this article: Rath H, Velichety SD, Lakshmi AY, Thyagaraju K, Havaldar PP. Morphometric Study of Posterior Cranial Fossa Using Computerized Tomographic (CT) Images. Acad. Anat. Int. 2019;5(1):1-5.

DOI: dx.doi.org/10.21276/aanat.2019.5.1.1

Source of Support: Nil, Conflict of Interest: None declared. 